\title{
On the US shale gas development business model for China's reference and inspiration
}

\author{
Shanghai LIU \\ Cooperation and Development Department \\ ChongQing University of Science \& Techlology \\ ChongQing 401331, China
}

\begin{abstract}
-shale gas exploration and development on the characteristics and patterns are very different from conventional gas, which need continuous drilling and production, the stable return on investment will be formed after a generation of scale. US shale gas development has its unique characteristics: pushed by the independent oil and gas producer at earlier time, after the major oil and gas companies to actively participate in and promote the shale gas development to the scale of industry; each block involved in mergers and acquisitions activity by number of companies; technology services company specialization and multi-force participation and collaboration to jointly promote the development of shale gas resources. But the US shale gas development hardware and software conditions are difficult to replicate in China; through investment or joint venture in the United States do not necessarily get the core technology. China has the advantages of shale gas development; we should learn the advanced management mode of operating experience from US and on the basis of selecting, absorbing, innovating foreign advanced management experience and business model to accelerate the development and utilization of China's shale gas resources.
\end{abstract}

Keywords- United States; shale gas; operating experience; management mode

\section{INTRODUCTION}

Our shale gas has huge Potential development, accelerate the shale gas development which has significance for protecting of national energy security, improving energy structure and people's living standards and promoting economic and social development, environmental protection. Shale gas is a clean, efficient energy resources and chemical raw materials; to accelerate the pace of industrial development of shale gas is useful to help improve the energy structure, people's quality of life and standard of living.

\section{A. promote economic and social development}

Shale gas exploration and development in southern China were located in favorable hill areas like Changning, Weiyuan- low mountain areas; there is inconvenient traffic, and inaccessible underdeveloped pipeline network. Largescale exploitation of shale gas needs to build gas gathering station, centralized processing stations, compressor stations and other ground engineering facilities, Sinotrans also needs to build pipelines, roads, railways and other facilities. As a major energy infrastructure industry, shale gas exploitation could stimulate the development of related industries and fields, reduce energy costs and improve industrial competitiveness, increase employment opportunities, labor income, GDP and taxation, to promote local, regional and national economies social development.

\section{B. promote environmental protection}

Main component of shale gas and conventional gas is basically the same, compared with the same burning fossil fuels coal and oil; shale gas emissions of pollutants are much lower than coal and oil.

\section{THE CHARACTERISTICS AND MODE OF SHALE GAS EXPLORATION\& DEVELOPMENT}

Different from conventional gas, shale gas development has low production of single well, low recovery, production decline, long production cycle characteristics, which determine the development of shale gas drilling sustained only through continuous production, generate economies of scale to form a stable return on investment. Shale gas exploration and development of the unique characteristics mainly in the following aspects: First, shale gas development need to take the scroll mode. Shale gas is in wide distribution, small porosity, low permeability, difficult development, it's not easy to reserve two wells through a proven, so the operator will often concentrated in a zone to play a number of gas wells and in the same period of exploration evaluation and development, the implementation of development rolling.

\section{CONSTRAINTS OF SHALE GAS DEVELOPMENT}

The main reason for the rapid development of US shale gas industry is active and effective policy support, advanced technology and services, open competitive environment, a sound market regulation, advanced network facilities. Compared to the United States, the current constraints of our shale gas development are mainly as follows: lack of an active and effective policy. US active and effective policy support, which greatly promoted the development of its shale gas industry. Our country has also introduced a series of preferential policies for low-grade coal bed methane and some oil and gas resources, but with low-grade resources for 
shale gas is still a lack of active and effective policy support. It is in complex geological conditions. Geological conditions of shale gas is much more complex than US, especially in deeper burial of beneficial marine shale, combined with complex terrain, population density and lack of water, limiting the pace of development of the shale gas industry. Resource base is countless. Currently, there are many units or agencies estimated and predicted the shale gas resource potential, but these shale gas resources in the huge difference, the mainly reason is lacking of support for shale gas development practice data and information and lack of core technology. After several years of research and development, China has initially mastered the basic techniques of shale gas development, but these are far from sufficient to meet the technical needs of the development of shale gas, especially lack of resources for the shale gas resource evaluation of the geological characteristics of horizontal drilling and multistage fracturing, cracks comprehensive monitoring and other key core technology.

\section{SHALE GAS EXPLORATION AND DEVELOPMENT PATTERNS}

On the exploration and development mode, shale gas and conventional gas wells also are very different. First, take the "factory assembly line" mode of operation. Shale gas wells are different from previously cluster wells which need scale and large volume transformation for entire of underground reservoirs by group wells, proceed with integrated development of the reservoir, this industrial-scale mining can be cost effective. Second, there is a complete production process. In the United States, the development of shale gas potential are generally divided into four stages proven, optimization, scale, re-evaluated, each stage has a corresponding development strategies and metrics. Through this series of operations, the potential of the block to get the maximum reasonable evaluation and development, which can maximize production. Third, pay attention to shale gas and conventional resources distinction. Due to the special nature of shale gas, companies generally regarded shale gas and conventional resources separately, only share market, finance, human resources, information technology, legal and supply chain, and other service businesses. According to the characteristics of shale gas development, manufacturers must ensure the stability of the size of the assets in the whole production process, and improve decision-making procedures, controllable cost pressures and ongoing management system.

\section{EXPERIENCE OF US SHALE GAS EXPLORATION AND DEVELOPMENT}

Unconventional oil and gas development in general can have two ways: First, the large diversified international oil companies to act as dominant, its deep pockets can afford the early risk, it can take a breakthrough in the field of new technologies such as capital-intensive shale gas industry; Secondly, smaller capital, technical expertise, commitment to the area of exploration and production business enterprises to take drilling risks, the first exploration into the frontier, the point is that the government must be given preferential conditions in all respects. [1] US shale gas exploration and development market is fully open, the coexistence of more than 8,000 medium and small enterprises, and market competition. Most blocks are controlled by small US energy companies and various funds, 85 percent of shale gas is produced by small and medium companies. [2] Therefore, the development of unconventional resources in the United States is taking the second road, which formed a unique feature of US shale gas development.

\section{A. Environment risk control measures of US shale gas development}

In May, 2012 the International Energy Agency (IEA) released the "golden age of gas golden rule" (Golden Rules for a Golden Ageof Gas) special report [5], which pointed out the development of natural gas is about to enter a golden age, but the premise is able to make profit at the same time, in an environmentally friendly way to reserve huge of unconventional gas resources (shale gas, tight gas and CBM) exploitation. Today the United States as the country's largest shale gas, its environment has been the practice of risk control measures, including government regulation and development of environment-friendly technology. American experience shows that through reasonable regulatory regime and evolving technology we can control the environmental risks of shale gas development and achieve environmentally friendly development of shale gas.

US take a basis of better environment development for conventional oil and gas regulatory system which aimed on new regulatory measures for shale gas development characteristics. In the early stages of development, the US government did not take special regulatory policies for shale gas development, but rather than introduce the regulatory framework of conventional natural gas in shale gas regulation, which including related environmental regulation. In recent years, with the increasing scale of shale gas development, triggering an increase in environmental disputes, the US government increasingly stringent regulation of shale gas development. The federal government is trying to implement a more stringent regulatory environment and production by modifying parts of the law, requiring developers to strengthen environmental protection investment in shale gas, put more risk-averse, and solutions to problems. For the hot issues of public concern, the United States issued a hydraulic fracturing operation process federal air pollution control standards, and is preparing a series of measures to increase the transparency of shale gas development process, including mandatory disclosure of shale gas development in the fracturing fluid usage, recommends the establishment of state government agencies wastewater discharge standards, the establishment of groundwater detection mechanism. 


\section{B. US shale gas development model has the feature of "state-based, federal regulation"}

American traditional oil \&gas laws and regulations are also applicable for development of shale gas. US Environmental Protection Agency has developed most of the federal law, but the development of federal owned lands has been mainly responsible for the Bureau of Land Management and forest service. When the two laws conflict with federal laws take precedence, and when the federal standards are below the state standard while two sets of regulations. Custody of interstate energy management activities also belong to the federal and state government levels management. On shale gas regulation, the federal government through the environment and interstate pipeline access regulation limited involvement, but where shale gas extraction, mining and gas standards when actually placed under the custody of the state government. In addition, US land rights and mining rights are separate from each other. On private land, the developer must sign a lease with mineral rights altruistic; the drilling and laying of pipes, to sign an agreement with the land owners, state regulatory agencies to obtain permits. For public lands, federal law will have enforcement planning and management, planning to audit once every 10 years, extensive public participation. Private companies can also acquire exploration rights on public lands through competitive bidding, but need to pay the appropriate use of mineral rent to the Government.

European shale gas development exhibits a very high enthusiasm, hoping to get rid of long-term dependence on Russian energy supplies. The European professional organizations estimate that by 2030 the EU can exploit shale gas 15 billion $\mathrm{m} 3$ per year. Currently, a number of oil companies have begun to look for shale gas in Europe, where Exxon Mobil Corporation has started drilling in Germany, Chevron Corporation and ConocoPhillips began exploration in Poland, the Austrian company OMV near Vienna test geological structure, Shell will be targeted in Sweden. According to the last year's survey of US Department of Energy, Poland's shale gas reserves sufficient for 300 years' use. Poland has always been heavily dependent on import of Russian gas; therefore, the country's shale exploration licenses have been issued. India's natural gas company and its headquarter Carrizo Oil \& Gas Company in Houston had carried out a binding agreement by the end of September 2011 , invest \$9500 million to purchase 20\% rights of Carrizo in the Eagle -Ford shale gas blocks. Tripathi, chairman of India's natural gas company said the acquisition will help the Indian master advanced technologies of shale gas development as soon as possible, India and the United States will also work together to find opportunities for shale gas development in India and other countries. November 2009 , the two sides signed a memorandum on cooperation in the field of shale gas. Then on this basis, the two sides formulated and signed the <<US State Department and China's National Energy Administration of Sino-US shale gas resources action plan.>> On May 26, 2010, the two countries issued a joint statement of energy security cooperation, one of the issues is to strengthen the bilateral cooperation in the field of shale gas. 2012 Land and Natural Resources Geological Survey said the country must vigorously strengthen shale gas, coalbed methane, oil shale, tight sandstone gas, oil sands and other unconventional energy resources survey and evaluation and development of technical research, in particular, to accelerate the shale gas industry's rapid development.

\section{IMPLICATIONS FOR CHINA}

At present, China has entered a period of high pollution events, the masses of the environmental sensitivity is increasing. Multiple features for extraction shale gas development will also increase the difficulty of environmental control and government regulation, and we must pay highly attention to it, to avoid any major pollution incidents and group events during shale gas development process, to prevent the development of shale gas industry impact. Government must be open access, while the regulatory system innovation, to assume regulatory responsibility. Policy design ideas should take shale gas regulatory environment as an important tool to promote the shale gas industry as healthy and smooth development. Meanwhile, for the urgency and specificity of shale gas development, the regulatory system, regulatory capacity building, funding mechanisms for the protection of information communication mechanism, should deploy and design regulatory framework for shale gas environment development.

Establishing stringent technical standards, reliable and comprehensive assessment should build rigorous technical standards, before large-scale development, increase efforts to assess shale gas development, the exploration of shale gas resources assessment and regional water planning and environmental impact assessments together, to have a comprehensive assessment of the feasibility of mining. Shale gas development should be cautious and avoid the first development, pollution first, then the path of governance.

\section{CONCLUSIONS}

Exploration of shale gas resources in China belong to the initial stage and face a completely different environment from the United States. Mineral rights management, government regulatory framework, the development model and the relative concentration of the gas industry oil and gas exploration rights are different from the United States. Our government should learn from the successful experience of other countries, at the same time, combined with China's national conditions and to be innovative, to create a more favorable policy environment, and improve related policies and regulations. Establish a complete monitoring system to mobilize the enthusiasm of the oil and gas companies' exploration and development of shale gas resources, and promote the healthy and orderly development of China's shale gas, allowing developers to take advantage of the resources rules to follow, according to the law to protect our energy supply safety. 


\section{References}

[1] Yuewei Feng, US shale gas development Strategy - American shale gas Dream [J] International Petroleum Economics, 2012, Z1:.. 92-100 $+182-183$

[2] Jiaru Chen, Wei Du, US shale gas development in the business model and management experience $[\mathrm{J}]$ International Petroleum Economics, 2012,10: $54-61+110$.

[3] Wei Wang. Law\& system research for Chinese shale gas resources development and management [D]. China Geosciences University (Beijing), 2012.

[4] Yan Li, Jiao Bo Mou Inspiration of foreign shale gas development practices for China [J] Chinese mining, 2013,03: 4-7 + 19.

[5] Yongtao Meng. Research and application for Shale gas horizontal well oil-based mud system [D]. Yangtze University, 2013.
[6] Xia Sun rebalancing US shale gas development and the global energy mix [J] International Petroleum Economics, 2013,12: 21-24 + 103.

[7] Jiping Pan. Shale gas development situation and prospects Reflections on the promotion of the development of shale gas resources [J]. International Petroleum Economics, 2009, 11: 12-15 + 90-91. 